\title{
Electronic Control of Fuel Mixture Preparation and Injection in Internal Combustion Engines
}

\author{
Roman Gogola ${ }^{1, *}$, Arpád Kósa ${ }^{2}$ \\ ${ }^{1}$ Institute of Automotive Mechatronics, Faculty of Electrical Engineering and Information Technology, \\ Slovak University of Technology, Bratislava, Slovakia \\ ${ }^{2}$ Institute of Electronics and Photonics, Faculty of Electrical Engineering and Information Technology, \\ Slovak University of Technology, Bratislava, Slovakia \\ *Corresponding author: roman.gogola@stuba.sk
}

Received September 12, 2014; Revised October 02, 2014; Accepted October 24, 2014

\begin{abstract}
This article deals with the issue of efficient fuel mixture preparation and injection control in internal combustion engines. Based on physical models a numerical model had been proposed and developed to enable simulations of the solved processes. A single cylinder engine model for transient simulations were developed using the Lotus Engine Simulation software. An engine control unit had been designed for the single cylinder engine model that controls the fuel injection dose at a certain engine load based on the information stored in the ECU. The effect of engine speed and throttle body opening on the fuel injection process was tested. Transient simulation results obtained from Lotus Engine Simulations were verified using the Matlab/Simulink ${ }^{\circledR}$ software environment.
\end{abstract}

Keywords: electronic control unit, internal combustion engine, fuel injection, injection map, Lotus Engine Simulation, Matlab-Simulink

Cite This Article: Roman Gogola, and Arpád Kósa, "Electronic Control of Fuel Mixture Preparation and Injection in Internal Combustion Engines.” American Journal of Mechanical Engineering, vol. 2, no. 7 (2014): 231-238. doi: 10.12691/ajme-2-7-12.

\section{Introduction}

Microprocessors (microcomputers) have become the heart of multiple control systems in the field of automobile technology. These microprocessors in cooperation with others are key components of the engine control unit, also known as Electronic Control Unit. Nowadays electronic devices are integrated into each automobile for various technological purposes, hence for the management of fuel injection and combustion in engines, and are projected to an increased use of electronics in the future. As a matter of fact, electronics are also used for various automotive applications such as the powertrain and vehicle motion control, driver and passenger safety and environmental communication for navigation.

Key component of interest in the automotive industry is the engine and its properties. The design of the engine today and also in the future will always depend on three main requirements such as the reduced fuel consumption, implementation of emission regulations issued by the European Union and the vehicle design. Modern trends in the automobile construction are based on requests for increasing passengers and driver comfort, vehicle handling, safety, and ultimately a higher vehicle utility value.

According to these requirements we can assume a decreasing trend of the automobile power unit space, in this particular case of the internal combustion engine. Therefore, as the main internal combustion engine production requirement, an increasing engine power by the engine stroke volume is expected.

The aim of this work is to propose and solve a numerical model of the electronic fuel injection design in an internal combustion engine regulated by a control unit in accordance with necessary physical conditions and the stoichiometric ratio control design. Important requirements, thus the control and reduction of exhaust emission gases, higher engine performance and effective fuel supply were also examined.

\section{The Importance of Fuel Mixture Preparation for the Spark-Ignition Engine Operation}

Problems in the past with fuel mixture preparation by carburetion forced the constructors to implement the idea of a fuel injection solution into the engine. High demands on high quality fuel mixture preparation procedures particularly in terms of performance improvement, fuel consumption reduction and especially low environment pollution required more and more complicated carburetor structures. These proposed systems of carburetor electronic regulation did not satisfy all the requirements and rather to simplify they complicated the whole fuel mixture preparation procedure. As followed the gasoline injection as a substitute system was more frequently used. 
In the case of internal combustion engines, the fuel mixture is prepared outside the workspace cylinder. For the preparation procedure components like the carburetor, injection equipment and gasifier (for gaseous fuel) are used. The injection equipment is classified into single point, multi point and direct injection systems (Figure 1.) The direct fuel injection system is an equipment in which the gasoline is directly injected into the combustion chamber (Figure 1). The Gasoline Direct Injection system (GDI) was introduced in 1997 by Mitsubishi. The production of this system has begun later in Europe under the name FSI (Fuel Stratified Injection), by Volkswagen. Since then the FSI system is evolving rapidly and has a key role in the fuel injection system production.

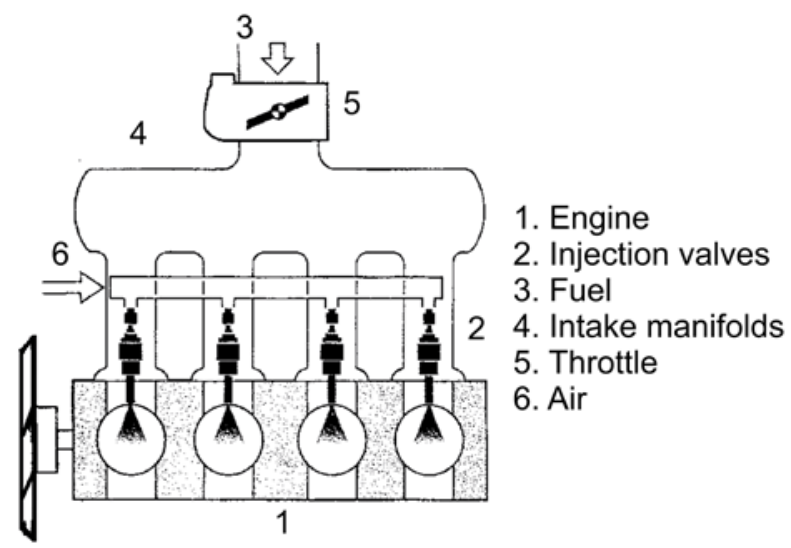

Figure 1. Schematic view of the Gasoline Direct Injection system [1]

The fuel injection procedure ensures the mixture preparation for spark-ignition internal combustion engines that burn homogeneous mixtures prepared from liquid fuel and air. In these systems the fuel under pressure of 0.2 to 1 bar flows through a nozzle with a small diameter that provides fuel atomization into small pieces, hence its evaporation. In comparison with the carburetion process the fuel injection provides the following benefits:

- Smaller hydraulic resistance of the induction engine tract

- The mixture distribution uniformity in the cylinders

- Better fuel atomization

- Higher engine power

- Improved fuel efficiency and lower emissions

- Better engine start up

- Greater safety in terms of fire

Carburetor systems will be eventually pushed out from production, because injection systems are ensuring a better fuel economy, dynamic engine characteristics and low fuel consumption. The usage of the direct fuel injection system can reduce fuel consumption by $5-40 \%$ while it also reduces the exhaust emissions of $\mathrm{CO}_{2}$.

\section{Physical Design of the Injection Process Model}

\subsection{Mixture of Fuel and Air and the Ideal Stoichiometric Ratio}

Ideal stoichiometric ratio of air to fuel for complete fuel mixture combustion is $14.7: 1$. This ratio is also known as the coefficient of excess air, thus the value of $\lambda=1$, which is calculated according to the number of oxygen atoms required for a complete hydrocarbon atom oxidization in the fuel. Different air to fuel combinations can provide different engine properties, hence for maximum power $\lambda=$ 0.82 (12:1) and a minimum consumption $\lambda=1.1$ (16:1). Certain conditions can also reduce exhaust emissions. The influence of the excess air coefficient $\lambda$ on the engine power $\mathrm{P}_{\mathrm{e}}$ and the specific fuel consumption $\mathrm{m}_{\mathrm{pe}}$ is shown in Figure 2.

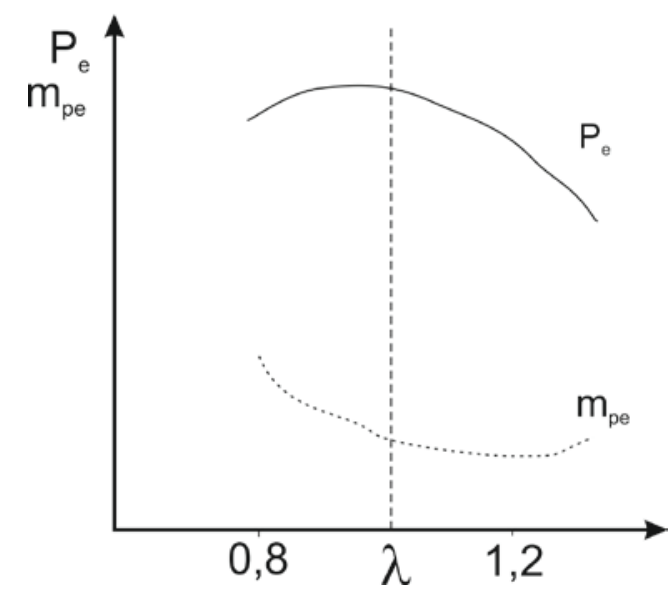

Figure 2. Effect of the air excess coefficient $\lambda$ on engine power $P_{\mathrm{e}}$ and specific fuel consumption $m_{\mathrm{pe}}$ [1]

\subsection{Requirements of the Electronically Controlled Fuel Mixture Preparation Design}

The electronic fuel mixture control is used to effectively manage the preparation and injection of the fuel mixture, furthermore the ignition and exhaust emission. As an example for the engine management system the Motronic ME 7 from Bosch was examined, as shown in Figure 3.

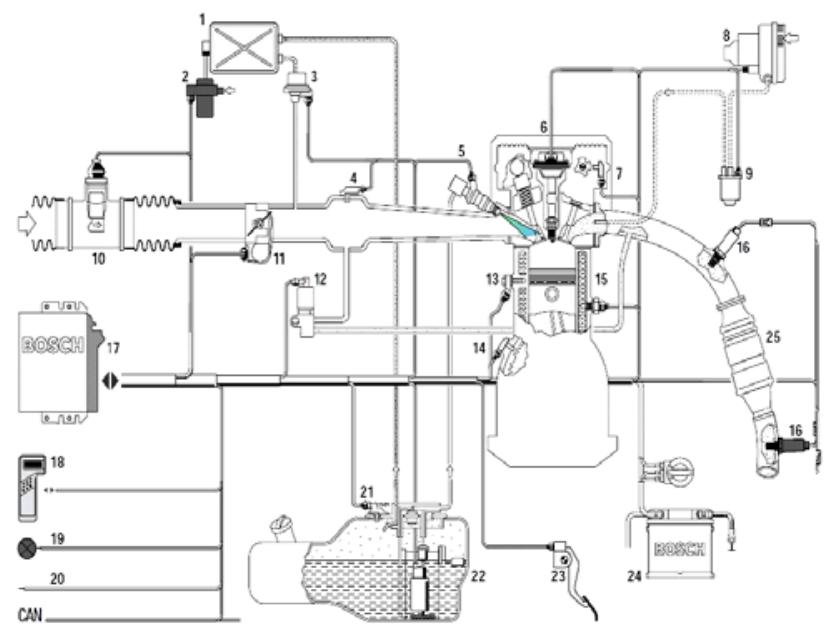

Figure 3. Engine management with On-Board Diagnostics (OBD) [5]: 1 - canister, 2 - fuel filter, 3 - valve for venting, 4 - pressure manifold, 5 fuel injector with fuel tank, 6 - ignition coil and spark plug, 7 crankshaft position sensor, 8 - pump air (secondary), 9 - secondary air valve, 10 - mass air meter, 11 - electronically controlled throttle, 12 EGR valve, 13 - knock sensor, 14 - engine speed sensor, 15 - coolant temperature sensor, 16 - oxygen Sensor, 17 - control unit (ECU), 18 interface for diagnostics, 19 - LED diagnostics, 20 - immobilizer, 21 pressure sensor in the fuel tank 22 - fuel pump in the tank, 23 - position sensor and accelerator pedal module, 24 - battery 


\subsection{The Proposed Physical Model of the Injection Process}

The development of the fuel injection physical process needs to be supported by analysis of each component to ensure a proper approach. All these parts are then combined into a physical model unit as shown in Figure 4, which contains all the necessary sensor components to ensure a proper parameter monitoring for e.g. engine speed, engine and fuel temperatures, intake air quantity etc. These parameters are needed for the injection time calculation.

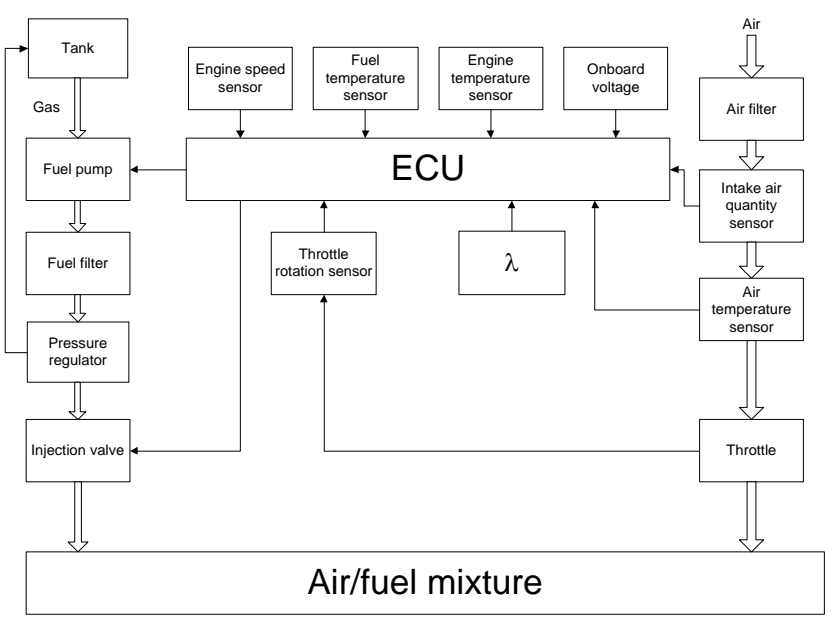

Figure 4. Physical model of the fuel injection process

\section{Injection Time Calculation}

\subsection{Calculation of the Basic Injection Time}

1 - The calculation of the basic injection time by the airflow method [2]

If the airflow sensor is integrated in the system, then the value of air mass $\left(A_{m}[\mathrm{~kg}]\right)$ is a known number, and it is possible to obtain the fuel quantity ( $M[\mathrm{~kg}])$ from the equation (1):

$$
M=\frac{A_{m}}{\lambda}[k g]
$$

where $\lambda$ is the air to fuel ratio.

Once we have calculated the value of $M$, thus the amount of injected fuel, the basic injection pulse width $(t$ [s]) is obtainable using the following equation (2):

$$
t=\frac{M}{R_{f}}[s]
$$

where $R_{f}[\mathrm{~kg} / \mathrm{s}]$ is the fuel injector delivery rate.

2 - The calculation of the basic injection time by the method of air density measurement [2]

If the air flow sensor is not integrated in the system, then the calculation of the basic injection time is realized by temperature sensors, speed sensor and the exhaust gas recirculation EGR. The following equation (3) is relevant:

$$
A_{v}=\left[\left(\frac{n}{60} \frac{D}{2} \eta_{v}\right)-E G R_{v}\right]\left[m^{3} \cdot s^{-1}\right]
$$

where $A_{v}\left[\mathrm{~m}^{3} \cdot \mathrm{s}^{-1}\right]$ is the air volume flow rate, $\eta_{v}$ is the volumetric efficiency, EGR $\left[\mathrm{m}^{3} . \mathrm{s}^{-1}\right]$ the exhaust gas recirculation and $D\left[\mathrm{~m}^{3}\right]$ the engine displacement.

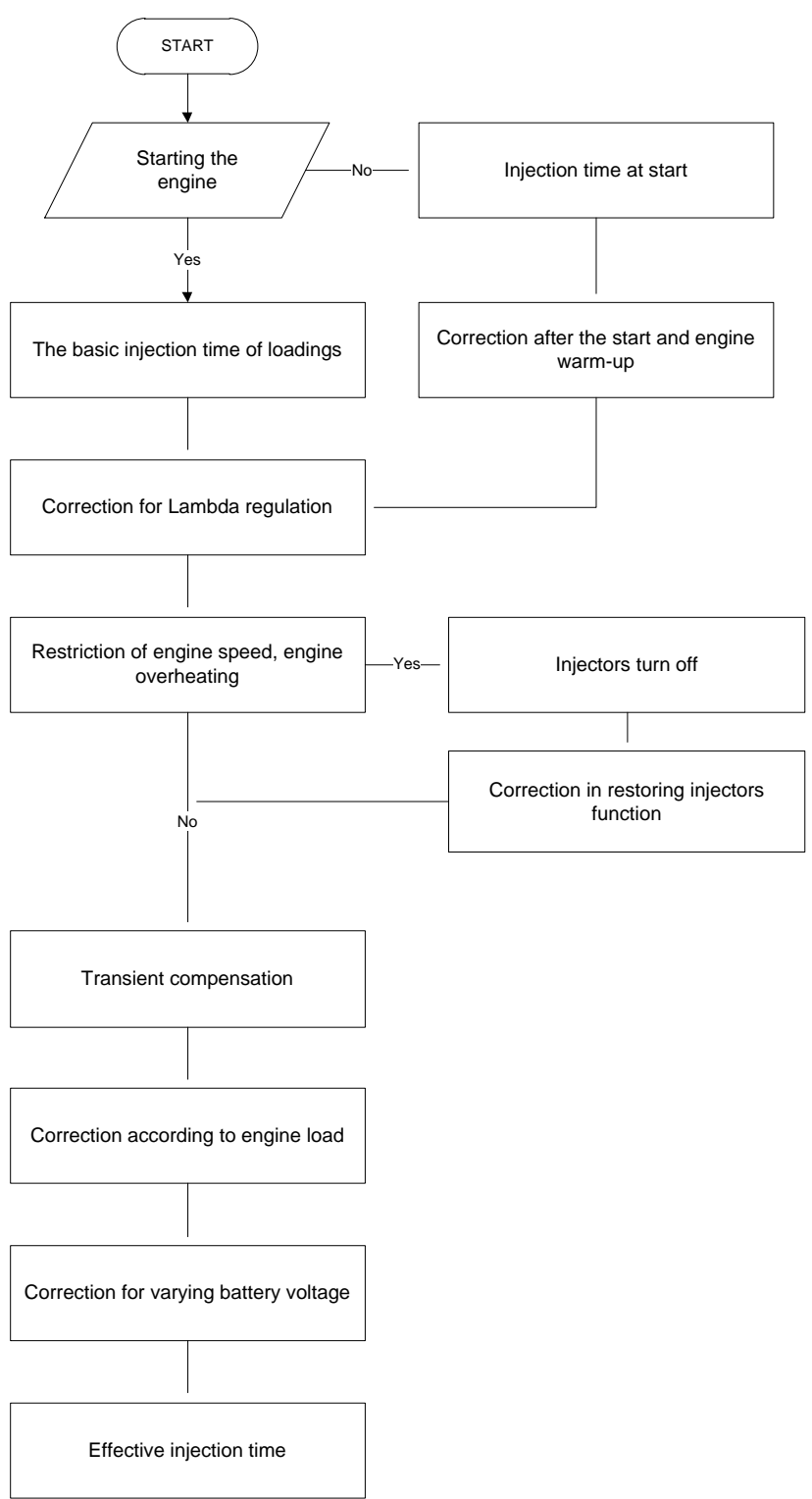

Figure 5. Flowchart of the fuel injection effective time calculation [2]

The density of air in the intake manifold is calculated by the following equation (4):

$$
\rho_{a}=\rho_{0} \frac{p_{i}}{p_{0}} \frac{T_{0}}{T_{i}}\left[\mathrm{~kg} \cdot \mathrm{m}^{-3}\right]
$$

where $p_{i}[\mathrm{~Pa}]$ is the pressure of the intake air, $T_{i}[\mathrm{~K}]$ is the temperature of the intake air, $\rho_{0}\left[\mathrm{~kg} . \mathrm{m}^{-3}\right], p_{0}[\mathrm{~Pa}]$ and $T_{0}[\mathrm{~K}]$ the density, pressure and temperature at sea level. If the mass flow rate of air $A_{r}\left[\mathrm{~kg} . \mathrm{s}^{-1}\right]$ is given by equation (5):

$$
A_{r}=\rho_{a} \cdot A_{v}\left[\mathrm{~kg} \cdot \mathrm{s}^{-1}\right]
$$

and the injected fuel mass rate equation (6):

$$
M_{r}=\frac{A_{r}}{\lambda}\left[k g . s^{-1}\right]
$$

than the injection time is calculated by the following equation (7): 


$$
t=\frac{M_{r}}{R_{f}} t_{r e f}[s]
$$

where $t_{\text {ref }}[\mathrm{s}$ ] is the reference injection time determined based on the engine RPM.

\subsection{The Effective Injection Time}

The effective period of fuel injection is determined after additional correction values recalculated. The correction values are calculated from special functions in which different engine operating conditions are taken into account. The calculation algorithm of the effective injection time is shown in the flowchart below (Figure 5).

It is important to notice that in case of a low amount fuel injection, a non-flammable mixture is prepared therefore the minimum fuel injection time limit has to be defined to prevent the formation of unburned hydrocarbons in the exhaust gases. During the engine start a separated calculation of the fuel injection time takes place which is not dependent on the load and engine speed.

Figure 5 shows the flowchart of the fuel injection mathematical model, which was proposed according to the study of various literatures. The flowchart contains all the necessary processing functions, which are needed for the fuel mixture preparation process of the automobile engine and parameter corrections of the injection time and lambda regulation. The output of the algorithm is the calculation of the mentioned effective injection time.

\section{Numerical Model of Fuel Injection Control In Petrol Engines}

Numerical models and software solutions of the fuel injection control system are useful tools for the study of the engine operating parameters and modifications. It is an effective way to determine and achieve the desired fuel injection properties. Furthermore, the use of the simulation software ensures not only optimal operating conditions and design solutions, but also a convenient financial and time efficient design realization.

The main advantage of the simulation software is the ability to test a vide number of variants, or the property to use optimization tools for the chosen parameters.
Although to achieve appropriate results, the optimized models need to be supported by measurements and verification procedures, the mathematical simulations are of great importance in the development of engines.

The proposed mathematical fuel injection model was realized in the software environment Lotus Engine Simulation (LES) followed by verification simulations in Matlab. The LES software is one of the most well-known tool for dynamic engine parameter modeling and it also contains a large database of input values and coefficients that can be used for simulation purposes.

\subsection{The Engine ECU}

Theoretically the engines' ideal amount and quality of injected fuel should be adjusted to the stoichiometric ratio, corresponding with the fuel mixture used in all operating conditions and for each fuel injection. Ideal injected fuel quantities are not always possible to achieve, because real time monitoring of the ideal stoichiometric ratio is hardly realizable. Therefore, the injected fuel control is regulated by the engine $E C U$. The engine ECU stores all the injection and correction maps that determine and electronically control the amount of injected fuel before the intake valves are activated.

The injection maps are containing all the values of injected fuel quantities for a specific engine speed and at a particular engine load. Further parameters that are regulating the actual injected fuel amount, such as throttle rotation speed, engine temperature, intake air temperature, fuel temperature, etc. are defined in the so called correction maps.

The compiled and simulated model of the engine control unit (Figure 6) included the mentioned injection and correction maps, where in the case of the correcting parameters the injected fuel was regulated only by the angular rotation velocity of the throttle because of a constant value of the ambient temperature parameter.

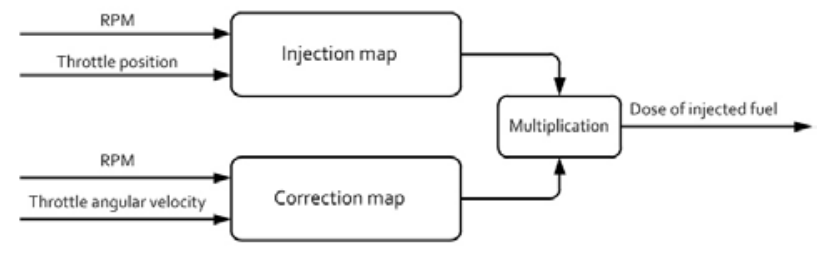

Figure 6. Schematic illustration of the of engine ECU

Table 1. Injection map of the engine ECU (indicates the amount of injected fuel in $\mathrm{mm}^{3}$ )

\begin{tabular}{|c|c|c|c|c|c|c|c|c|c|}
\hline \multirow[t]{2}{*}{ RPM $\left[\min ^{-1}\right]$} & \multicolumn{9}{|c|}{ Throttle angle $\left[{ }^{\circ}\right]$} \\
\hline & 5 & 10 & 20 & 30 & 45 & 60 & 70 & 80 & 90 \\
\hline 1000 & 1 & 8.63 & 26.94 & 29.82 & 30.3 & 30.48 & 30.78 & 30.8 & 30.8 \\
\hline 1500 & 1 & 5.77 & 24.2 & 29.03 & 30.96 & 30.92 & 30.62 & 30.59 & 30.59 \\
\hline 2000 & 1 & 4.47 & 21.12 & 27.54 & 30.81 & 32.46 & 33.31 & 33.41 & 33.4 \\
\hline 2500 & 1 & 3.65 & 19.29 & 27.03 & 31.05 & 32.35 & 32.57 & 32.53 & 32.57 \\
\hline 3000 & 1 & 3.23 & 17.33 & 25.9 & 31.04 & 32.35 & 32.5 & 32.48 & 32.51 \\
\hline 3500 & 1 & 2.5 & 15.68 & 23.16 & 28.63 & 30.01 & 30.14 & 30.12 & 30.15 \\
\hline 4000 & 1 & 2.04 & 15.16 & 23.07 & 29.85 & 31.2 & 31.32 & 31.2 & 31.35 \\
\hline 4500 & 1 & 2.06 & 14.67 & 22.55 & 29.98 & 31.72 & 31.99 & 32.01 & 32.02 \\
\hline 5000 & 1 & 2.06 & 13.79 & 22.16 & 30.59 & 33.06 & 33.56 & 33.61 & 33.63 \\
\hline 5500 & 1 & 1.87 & 12.9 & 20.98 & 30.3 & 33.69 & 34.59 & 34.25 & 34.29 \\
\hline
\end{tabular}


Table 2. Correction map of the engine ECU

\begin{tabular}{|c|c|c|c|}
\hline \multirow{2}{*}{ RPM $\left[\mathbf{m i n}^{-1}\right]$} & \multicolumn{2}{|c|}{ Throttle angular velocity [\%/s] } \\
\cline { 2 - 4 } & $\mathbf{( - 2 0 0 0 0 , - 3 5 0 )}$ & $<-350,350>$ & $\mathbf{( 3 5 0 , 2 0 0 0 0 )}$ \\
\hline 1000 & 0.8 & 1 & 1.2 \\
\hline 1500 & 0.8 & 1 & 1.2 \\
\hline 2000 & 0.8 & 1 & 1.2 \\
\hline 2500 & 0.8 & 1 & 1.2 \\
\hline 3000 & 0.8 & 1 & 1.2 \\
\hline 3500 & 0.8 & 1 & 1.2 \\
\hline 4000 & 0.8 & 1 & 1.2 \\
\hline 4500 & 0.8 & 1 & 1.2 \\
\hline 5000 & 0.8 & 1 & 1.2 \\
\hline 5500 & 0.8 & 1 & \\
\hline
\end{tabular}

The determined injection map listed in the table (Table 1) below defines the injected fuel quantities $\left(\mathrm{mm}^{3}\right)$ at a given engine speed (RPM) and different angles of the throttle opening. The correction map of the engine control unit is used to regulate the amount of injected fuel, depending on the angular velocity of the throttle rotation. The correction values of enrichment or impoverishment of the fuel mixture are shown in Table 2.

\subsection{The Engine Control Model in the LES Software Environment}

The analytical simulations of the proposed injection and correction map were realized on a one cylinder engine model, which was designed using the LES software environment. The regulation process of the injected fuel was tested and examined in transition mode and at a fully opened throttle by signal processing. Figure 7. shows the tested model of the one-cylinder engine.

\subsection{Fuel Injection Management Model in Matlab / Simulink ${ }^{\circledR}$}

The LES scheme was verified by a fuel injection management model, which was created in the software environment Matlab / Simulink ${ }^{\circledR}$. This model consists of physical and empirical relations based on which the intake manifold dynamics are calculated. The air-fuel ratio is calculated according to the mass flow rate division, hence by the intake air sucked through the intake manifold and the mass flow of the injected fuel. The target stoichiometric ratio for this model is 14.7. The oxygen sensor determines the amount of residual oxygen in the exhaust. The sensors deliver information to the control unit and are providing a feedback, hence a back-coupled regulation. When high rate of residual oxygen in the exhaust gas is present the amount of injected fuel is increased. It is evident that in the opposite situation the amount of injected fuel is reduced.

\subsection{Engine ECU in Matlab/Simulink ${ }^{\circledR}$}

The engine control unit - STATEFLOW (Figure 9) consists of six functional parallel components. The top blocks are illustrating each sensor element, hence the oxygen intake, pressure, throttle rotation and engine speed sensor. The remaining two function blocks, located at the bottom of the chart are sensor data converters, which set the operating mode of the system and execute regulation commands accordingly. The proposed model is synchronously communicating with the stateflow in the third period every 0.01 seconds. This allows quick action hit of the entire system.

\section{Throttle position Throttle angular velocity}

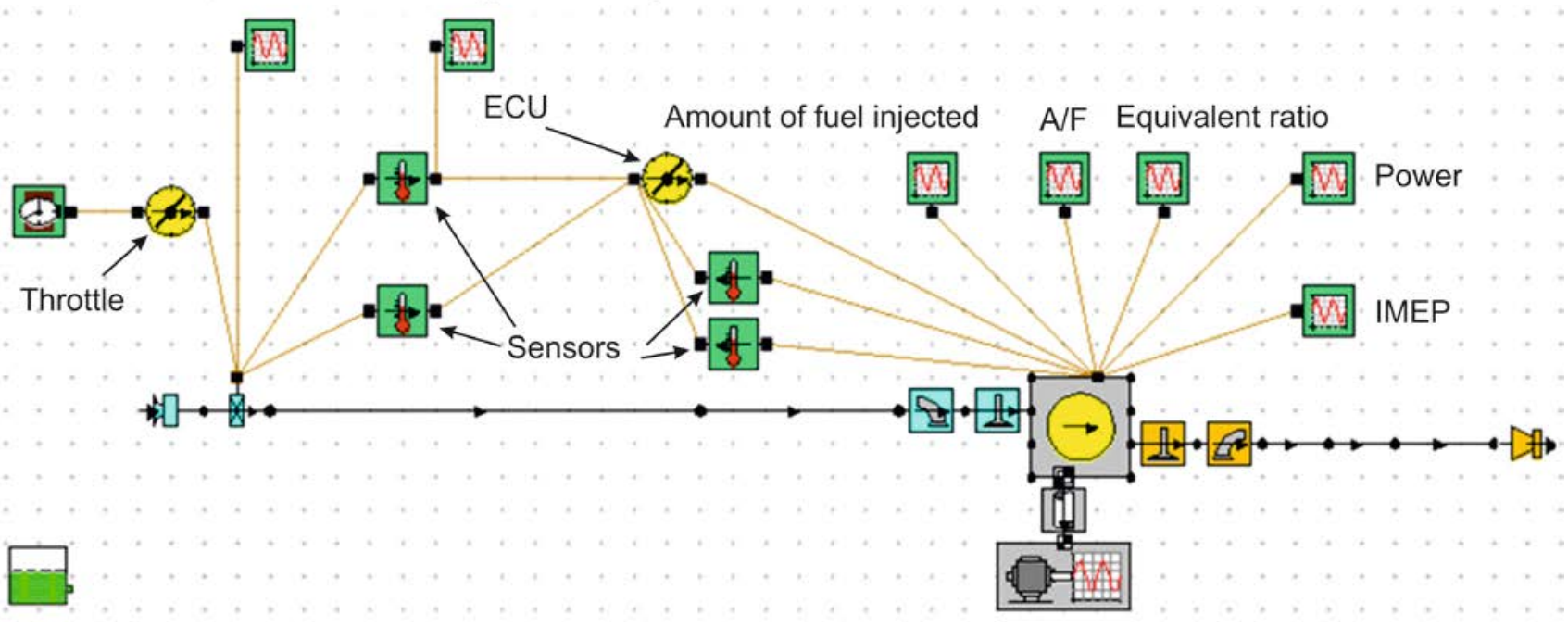

Figure 7. The schematic view of the engine control model realized in the LES software environment [3] 


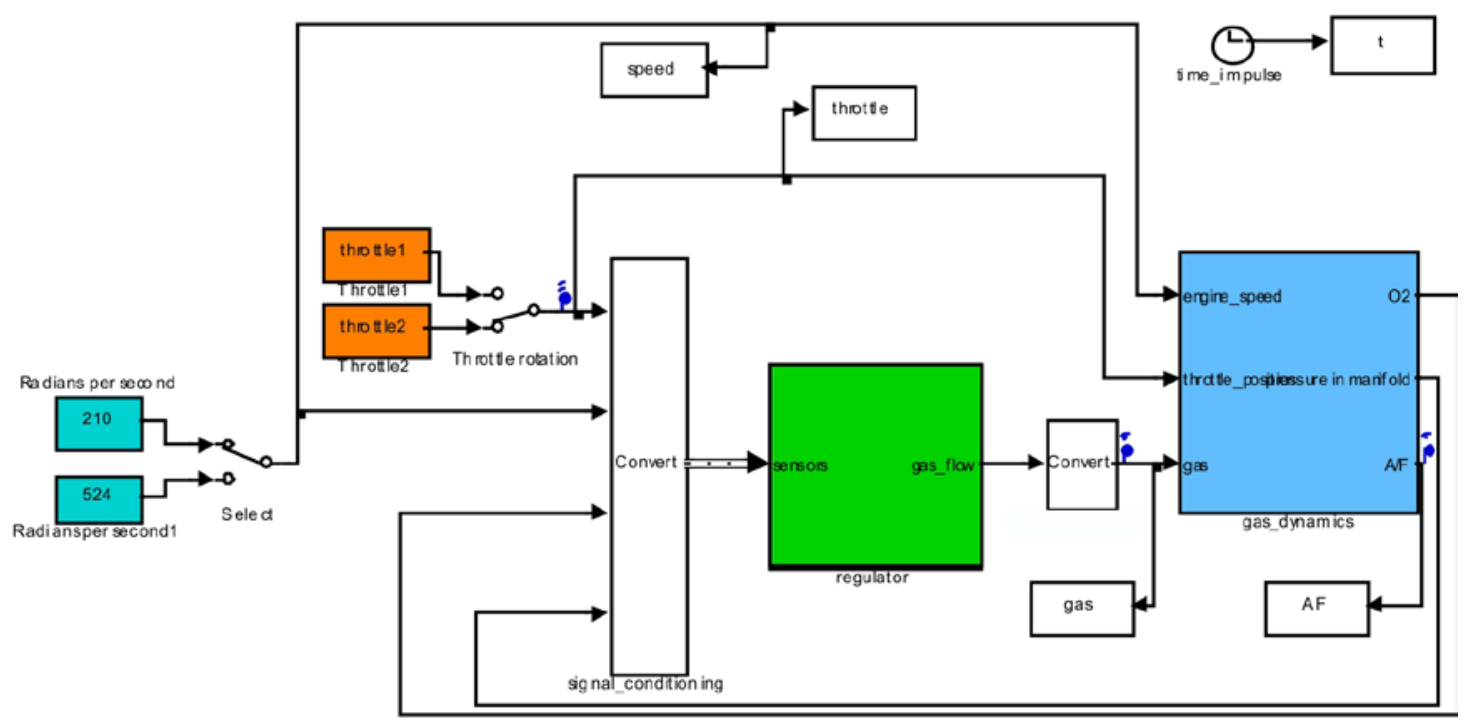

Figure 8. Schematic view of the fuel injection control system model in the Matlab / Simulink ${ }^{\circledR}$ software environment [4]

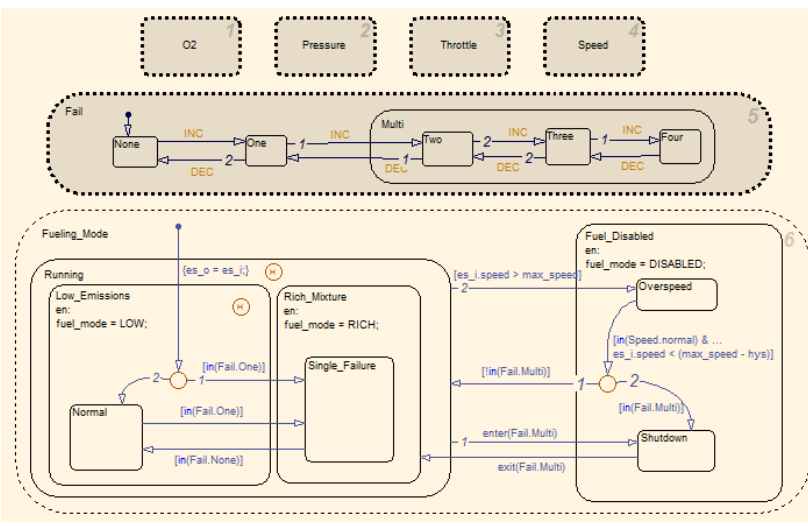

Figure 9. Matlab / Simulink $®$ ECU stateflow [4]

\section{Suitability Verification of the Proposed Management System}

Relevance of the proposed electronic management system for fuel mixture preparation and injection was investigated by injection process time simulations on the developed models also in the LES and Matlab/Simulink ${ }^{\circledR}$ software environments.

\subsection{Fuel Injection Process Simulation of the Single Cylinder Engine Model in LES}

A very important factor which is also needed to be investigated is the acceleration. The acceleration has a key role in the transverse mode, when rapid acceleration of all engine components and also the fuel mixture injection takes place. Acceleration, hence a quick burst on the accelerator in the model was achieved by a proper actuator component, in which the rotation angle of the fuel injection throttle was set. Two process types were investigated.

The first process simulation included a full opening angle of the throttle, thus from $5^{\circ}$ to $90^{\circ}$ angle rotation which was, followed by a full open-close mechanism approximately after one second (Figure 10).

The second process was similar to the first one but the opening sequence was followed by a partial closing and reopening simulation. More precisely the closing sequence at the first second of the simulation was realized with a $30^{\circ}$ throttle rotation (Figure 11 ).

The fuel injection parameter characteristics are used to verify the functionality and proper operation of the control unit. Figure 12 shows the time process of the injected fuel quantity by a specific engine speed. These characteristics were measured at various throttle rotation angles and opening closing processes according to the time simulations processes mentioned before.

At the first process the throttle was fully opened in the starting sequence of the measurement than closed and reopened. It should be noticed here that each opening mechanism caused a small peak in the fuel injection characteristics which was resulted by the time delay of the control units' correction procedure (Figure 12.).

Figure 13 shows the fuel dose injection second process at an engine speed of 2000 RPM where the throttle was partially closed with a $30^{\circ}$ angle rotation than fully reopened. As well as in the first case the correction map was applied and after a slight time delay the fuel dose was corrected, where peaks in the characteristics appeared exceeding the corrected values. According to these measured and simulated transient characteristics we can conclude that a fast correction time with lower accuracy was achieved.

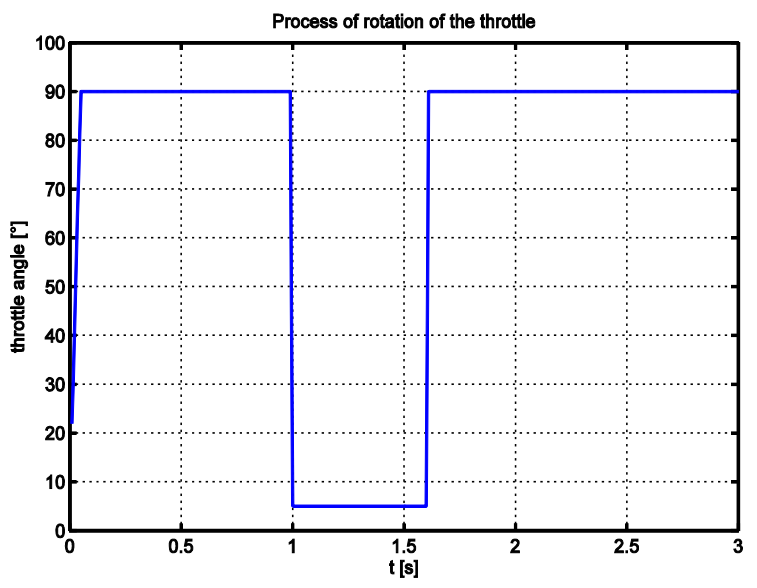

Figure 10. Full opening and closing angle, process time characteristics of the throttle rotation in LES 


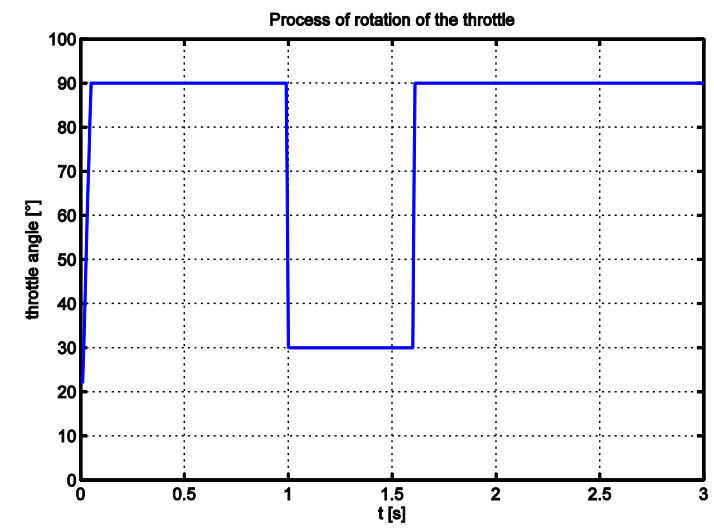

Figure 11. Full opening and $30^{\circ}$ closing angle, process time characteristics of the throttle rotation in LES

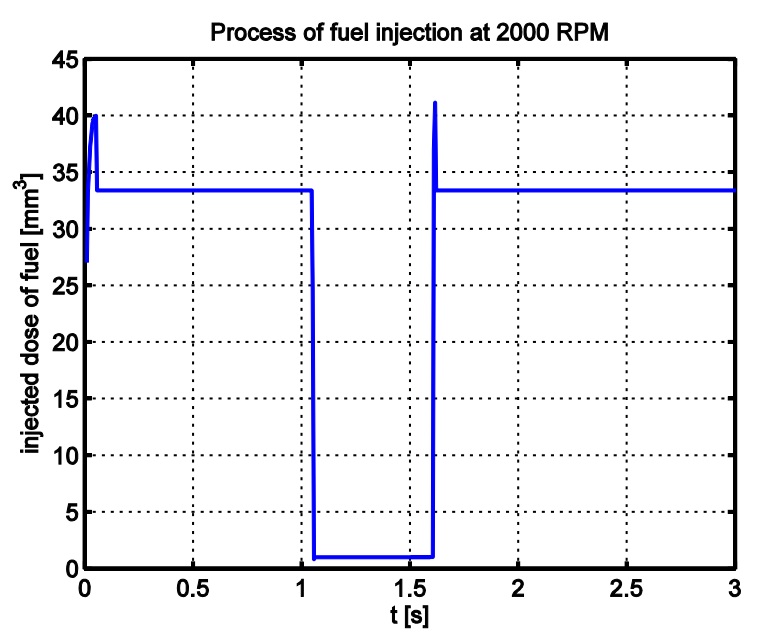

Figure 12. Process time characteristics of the fuel injection at 2000 RPM, by full opening and closing angle process of the throttle in LES

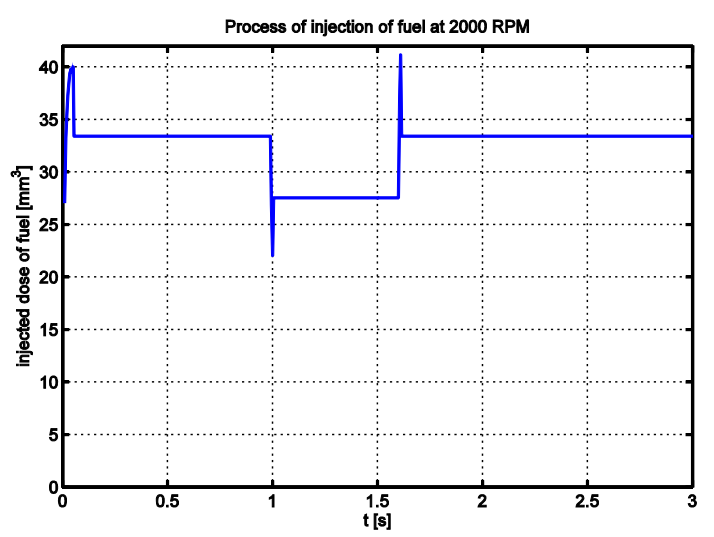

Figure 13. Process time characteristics of fuel injection at 2000 RPM, by full opening and $30^{\circ}$ closing angle process of the throttle in LES

\subsection{Simulation Verification in Matlab / Simulink ®}

To verify the correctness of the first simulation model we used an existing, but modified model to simulate the fuel injection in an internal combustion engine by the software Matlab/Simulink ${ }^{\circledR}$. The process of the throttle rotation was identical as in the case of the one-cylinder engine model. The throttle angle values were loaded from external files. The first simulation was carried out at a full throttle opening and closing procedure (Figure 14) while the second simulation included a partial closure (Figure 15).

The control unit in the Matlab/Simulink ${ }^{\circledR}$ simulation regulated the injected fuel dose by the correction map significantly slower than in the case of the LES simulation, hence different time process characteristics were measured. The regulation is indeed slower but in the other hand more accurate, thus no exceeding values appeared (see Figure 16. and Figure 17.). Figure 17 shows the second process of fuel dose injection with a $30^{\circ}$ rotated throttle at the closing mechanism.

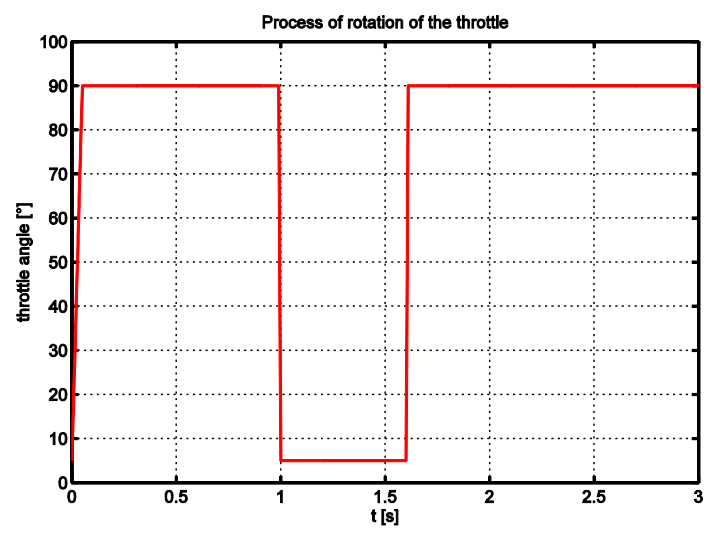

Figure 14. Full opening and closing angle, process time characteristics of the throttle rotation in Matlab/Simulink ${ }^{\circledR}$

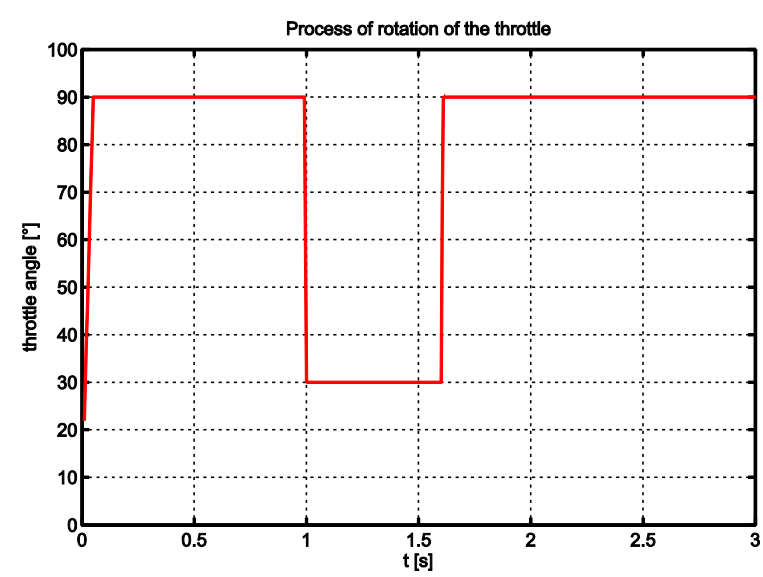

Figure 15. Full opening and $30^{\circ}$ closing angle, process time characteristics of the throttle rotation in Matlab/Simulink ${ }^{\circledR}$

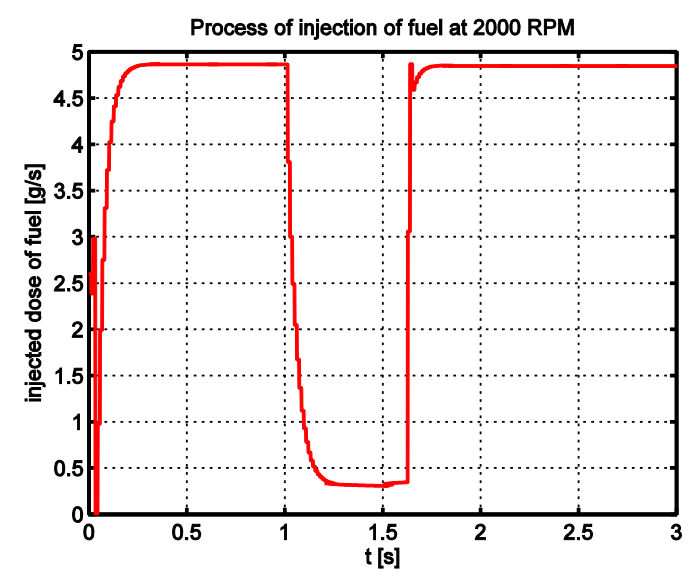

Figure 16. Process time characteristics of the fuel injection at 2000 RPM, by full opening and closing angle process of the throttle in Matlab/Simulink ${ }^{\circledR}$ 


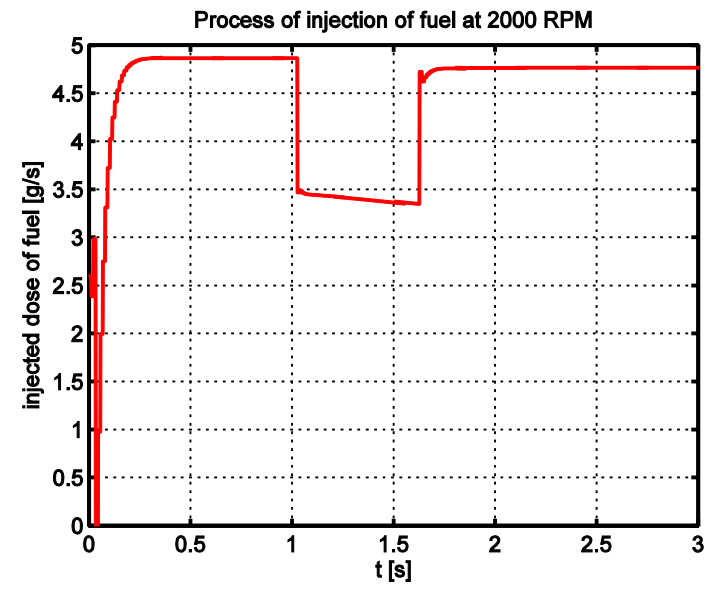

Figure 17. Process time characteristics of fuel injection at 2000 RPM, by full opening and $30^{\circ}$ closing angle process of the throttle in Matlab/Simulink ${ }^{\circledR}$

\section{Conclusion}

This article proposes a software model solution of a fuel mixture preparation and injection management system for internal combusition engines. Main effort was devoted to establish an efficient simulation model in the Lotus Engine Simulation software. To create an adequate model of a one-cylinder internal combustion engine we designed a control unit, which consisted of injection and correction maps for the adjustment of the fuel injection dosage by transition acceleration and deceleration. For the task of veification the software environment Matlab/Simulink ${ }^{\circledR}$ was used.

The functionality control was tested by transient measurement modes and evaluation of the resulted time characteristics of fuel dosage injection by throttle rotation angle at a specific engine speed. All these simulations were carried out also on the verification model in Matlab/Simulink ${ }^{\circledR}$ and the resulted curve characteristics and parameters were compared. The proposed model indicated a faster fuel dose injection correction carried out according to the determined correction map, but unfortunatelly resulted exceeded values at opening and closing processes. The verification model indicated slower fuel dosage injection correction but with more precise values.

Experimanetal measurements of the internal combustion engine are necessary to carrie out in order to completely verify the obtained simultaions.

\section{Acknowledgement}

The paper has been supported by the Slovak Scientific Grant Agency -VEGA No. 1/0534/12.

\section{References}

[1] VLK, F.: Automobilová elektronika 3: Systémy řizení motoru a převodu. 1. Brno: Prof. Ing. František Vlk, DrSc., 2006. 355 s. ISBN 80-239-7063-1.

[2] SUNWOO, M., SIM, H., LEE, K.: "Design and Development of an ECU and its Air-Fuel Ratio Control scheme”, Proc. IEEE-SAE International Congress on Transportation Electronics, Dearborn, MI, pp.508-514, Jun. 1998.

[3] Lotus Engineering Software, Group Lotus Plc, Norfolk, United Kingdom. Available from: http://www.lesoft.co.uk

[4] The model of the fuel system to simulate error conditions, available from: http://www.mathworks.com/

[5] Engine management with On-Board Diagnostics (OBD) available from: http://www.boschautomotive.com/en/fachliteratur/pdf/u228e.pdf 